\title{
The future of geriatrics: a public health perspective
}

\author{
Norman Vetter \\ University of Wales College of Medicine, Cardiff, Wales, UK
}

\section{Introduction}

Single organ therapy for medical specialties, general medicine and its subspecialties, has increasingly failed a number of groups of people over the last 200 years or so. The largest group were elderly people who were summarily dismissed from the Infirmaries from the days of their building as 'vagabond beggars, incurables and elderly'. ${ }^{1}$ The vagabonds at least were welcomed after 1948, when the NHS diverted attention from people's cheque books and on to their illnesses. However, other groups have continued to suffer from the tyranny of single organ care, notably the 'incurables', young chronically sick people and those who were not capable of 'getting better' immediately. The lack of good, consistent postmyocardial infarction advice, despite excellent research findings, ${ }^{1,2}$ and a lack of rapid admis$\operatorname{sion}^{3,4}$ and full rehabilitation services ${ }^{5}$ for stroke victims remain a matter for concern in general medicine. How will new changes in the NHS, especially the development of Primary Care Groups (PCGs) and Trusts affect geriatrics?

\section{Is geriatrics the right model for elderly people?}

Geriatric medicine is that branch of general medicine concerned with the clinical, preventive, remedial and social aspects of illness in older people. Their high morbidity rates, different patterns of disease presentation, slower response to treatment and requirements for social support call for special medical skills'. The purpose is to restore an ill and disabled person to a level of maximum ability and, wherever possible, return the person to an independent life at home. ${ }^{6}$

General rules for deciding upon effective

Address for correspondence: N Vetter, Department of Epidemiology and Public Health, University of Wales College of Medicine, Cardiff, Wales, CF14 4XN, UK. services have been put together by a large number of people. The framework that appears to have stood the test of time was put together by Maxwell':

\section{- Access to services}

- Relevance to the needs of the whole community

- Effectiveness for individual patients

- Equity.

- Social acceptability

- Efficiency and economy

These should be borne in mind, as well as the quality of the direct care provided by a doctor or nurse for patients

\section{Access to services}

Services given in the home or near to people are likely to be more accessible to patients than those given at a point for a large population. Smaller geriatrics hospitals have largely closed down in preference to district general hospital sites over the past 20 years or so. Where the geriatrics department has remained separate, it has usually been in poorer premises with poorer physical access, especially to older premises. Geriatrics appears to have lost out in this regard. Patients often have another type of problem with access to services when they try to find their way through complex appointment systems to see a consultant. However, geriatric care has been good at avoiding waiting lists, though this is a function of the fact that most admissions are emergencies.

Geriatricians still occasionally do domiciliary visits and a few work out of health centres, but this has not been common. In terms of access, such approaches are to be desired. Access to services can mean other things, for example, whether people or the professionals know about the service in question. There is little point in having a 
special clinic for a particular group of people if the publicity for it is bad. In the past such innovative schemes as night-sitter services and incontinence laundry services have foundered because of a perceived lack of demand, when lack of publicitiy was the culprit.

\section{Relevance to the needs of the whole community}

Primary care practitioners on PCGs have the advantage of being aware of the social background and pressures on at least some of the areas in which they work. Geriatricians, with their holistic approach to medicine, may find that they have some insights in common with PCG members which were missing from the health authority personnel.

UK general practitioners, as gatekeepers for the service, have been particularly effective in keeping down the demand for services, compared with countries where patients have open access to hospital care. Sometimes, however there appears to be an inherent agism in this parsimoniousness, which geriatricians may like to try to overcome through advising the local PCG.

\section{Effectiveness for individual patients}

Scientific testing of the effectiveness of care for elderly people still lags some way behind that for the middle-aged, due to agism among researchers. There is an increasingly expanding body of knowledge in this area, especially about the effectiveness of high-tech medicine for older people and in the area of rehabilitation, which was lacking in good scientific research until quite recently.

\section{Equity}

Equity is a central concept for geriatricians, for agism is rife within the health service, as recent studies have shown. Such agism may be subtle, such as the failure of a GP to refer for specialist care an elderly patient with renal failure, or perhaps more commonly, to wait until the disease is at a more severe stage than for younger people. PCGs will have to be kept straight on such matters.

\section{Social acceptability}

Geriatricians should be aware of the social acceptability of the treatment that they give or purchase for their patients. However, they are not always as aware of their patient's views on the acceptability of treatment or, for that matter, their social conditions as we might wish. ${ }^{8}$

\section{Efficiency and economy}

Geriatrics is not perceived as a high-cost specialty. In fact, high staffing ratios are important in geriatrics care, balancing somewhat the faster turnover in non-geriatrics wards. Overall, as far as it can be measured, the two probably cost about the same per patient.

In as far as some geriatrics departments are involved with cold orthopaedics, they must share some of the ridiculously long waiting-lists for assessment, operation and rehabilitation for an operation which, in terms of cost per QUALY, is one of the most efficient and effective in medicine.

\section{The future}

One of the problems within geriatrics is that the roles of geriatricians are often not clear. There are a number of models which may cross over. A commissioner on a PCG, keen to get the best value, might want to know more precisely what he or she is getting for their money. There appear to be five models, some of which cross over one another:

- General physician for older people

- Expert in complex pathology

- Specialist in holistic medicine for older people

- Expert at rehabilitation

- Expert at assessment for community care

Geriatric medicine has put on the agenda the differences between elderly and younger people in relation to acute inpatient care. I think geriatrics needs to make clear what its preferred sphere of influence is before purchasers, especially the new PCGs, can decide on how it fits into the treatment of ill people. Geriatricians may say that they are expert in all of the fields I have mentioned, but there are two dichotomies to be faced: the specialist vs. the generalist and the simple care of the aged vs. the care of complex problems at all 
ages. I do not think a geriatrics service in one place can perform all of these functions.

My personal preference would be for them to take over the general care of complex problems in all age groups.

\section{Reference}

1 Ross SD, Allen IE, Connelly JE et al. Clinical outcomes in statin treatment trials: a meta-analysis. Arch Intern Med 1999; 159: 1793-802.

2 Oldridge NB, Guyatt GH, Fischer ME, Rimm AA. Cardiac rehabilitation after myocardial infarction. Combined experience of randomized clinical trials. JAMA 1988; 260: 945-50.

3 Bath PM. The medical management of stroke. Int J Clin Pract 1997; 51: 504-10.
4 Rosamond WD, Gorton RA, Hinn AR, Hohenhaus SM, Morris DL. Rapid response to stroke symptoms: the Delay in Accessing Stroke Healthcare (DASH) study. Acad Emerg Med 1998; 5: 45-51.

5 Wein TH, Hickenbottom SL, Alexandrov AV. Thrombolysis, stroke units and other strategies for reducing acute stroke costs. Pharmacoeconomics 1998; 14: 603-11.

6 British Geriatrics Society Homepage. Aims. http://www.bgs.org.uk/aboutbgs.htm

7 Maxwell R. Quality assessment in health. BMJ 1984; 288: 1470-72.

8 Simpson M, Buckman R, Stewart M et al. Doctorpatient communication: the Toronto consensus statement. BMJ 303: 1385-87. 